\title{
When in doubt ... ask the patient: Patient-reported measures and prognosis in esophageal cancer
}

\author{
Stephen R. Broderick, MD, MPHS
}

\footnotetext{
From Division of Thoracic Surgery, Department of Surgery, Johns Hopkins University School of Medicine, Baltimore, Md.

Disclosures: Author has nothing to disclose with regard to commercial support.

Received for publication Feb 2, 2016; accepted for publication Feb 3, 2016; available ahead of print March 8, 2016.

Address for reprints: Stephen R. Broderick, MD, MPHS, Division of Thoracic Surgery, Department of Surgery, Johns Hopkins University School of Medicine (E-mail: sbroder7@jhmi.edu).

J Thorac Cardiovasc Surg 2016;151:1448-9

$0022-5223 / \$ 36.00$

Copyright (c) 2016 by The American Association for Thoracic Surgery

http://dx.doi.org/10.1016/j.jtcvs.2016.02.007
}

The choice of therapy for locally advanced esophageal cancer is often a difficult one for patients and providers. Despite available objective data, treatment decisions are often influenced by factors such as patient motivation, symptom burden, treatment goals, or social and emotional concerns, none of which are incorporated into prognostic models. Performance of validated health-related quality of life (HRQOL) measures before the initiation of therapy may provide a method of incorporating some of these otherwise unmeasured variables into the evaluation of patients with esophageal cancer.

In their article in this issue of the Journal, Kidane and colleagues $^{1}$ expand on the utility of validated HRQOL instruments in the evaluation of patients with esophageal cancer. The authors used data from 4 prospective trials involving patients with esophageal cancer for whom HRQOL measurements (Functional Assessment of Cancer Therapy-Esophagus [FACT-E]) were obtained before the initiation of any therapy. One hundred seventy-two patients with stage II or III disease were treated with curative intent and included in the primary analysis. Kidane and colleagues ${ }^{1}$ concluded that in these patients, higher baseline HRQOL scores were associated with an improvement in overall survival.

The evaluation of HRQOL is often fraught with inconsistencies in collection and incomplete data, leading to bias. A definite strength of this article is the uniform completion of the baseline FACT-E instrument in the setting of prospective clinical trials. Kidane and colleagues ${ }^{1}$ performed thorough statistical analyses evaluating the HRQOL score in 3 ways: as a continuous variable, a dichotomous variable, and by quartiles. They also performed a number of sensitivity analyses to address the robustness of their models. Furthermore, the multivariable logistic regression models included only data available prior to treatment decisions, making these models more applicable to actual clinical decision making than similar models using data gained later in the clinical process.

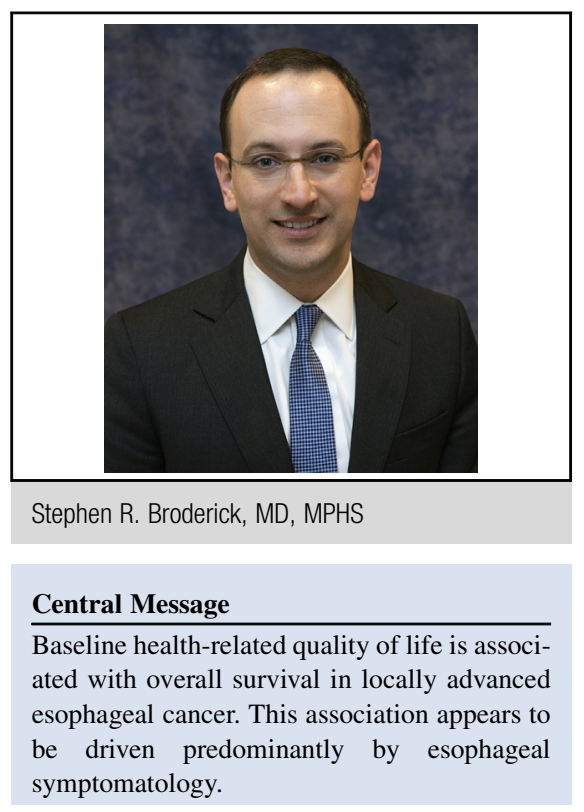

See Article page 1571.

It is striking that stage was not associated with survival in this study! The authors appropriately address this concern in their discussion section. The lack of association is likely due to the inclusion of only stage II and III patients in the primary analysis, as well as the fact that the study was not powered to detect a difference in survival based on stage. The inclusion of clinical stage for nonsurgical patients, while pathologic stage was used for those who underwent resection, further complicates any association between outcome and stage. Another limitation of the study is the fact that data were collected over an 18-year period in which significant advances have been made in the realms of medical oncology, radiation oncology, surgery, and endoscopic techniques.

The HRQOL instrument that was used in this article is the FACT-E. Previous studies ${ }^{2,3}$ have linked baseline HRQOL with survival in esophageal cancer, but these studies have used only global HRQOL instruments. The FACT-E instrument consists of a general instrument covering physical, functional, social, and emotional domains with the addition of a specific esophageal cancer subscale (ECS). ${ }^{4}$ The ECS includes 17 items focused on eating, swallowing, enjoyment of food, and a number of other upper aerodigestive tract symptoms. Kidane and colleagues ${ }^{1}$ used multivariate modeling to detect a significant 
independent association between baseline FACT-E score and overall survival after adjustments for age, stage, histologic type, and therapy received. In addition, they performed the same models with only the esophageal cancer-specific ECS and found an even stronger association with survival and improved model performance.

The stronger association between the ECS and survival suggests that the relationship between the broader FACT$\mathrm{E}$ and survival is driven primarily by patients' esophageal symptoms. This brings up the question of whether the FACT-E and ECS scores are really serving as a proxy for T-stage or esophageal tumor burden. Assessment of the other component scales of the FACT-E would be of interest to determine the degree to which functional, social, emotional, and overall physical well-being are associated with survival.

This article represents an important addition to the literature on locally advanced esophageal cancer. Associations between baseline quality of life and survival suggest that these assessments can be used to help inform patient decision making in the clinical setting. There is an old adage that says, "when in doubt ... ask the patient." Perhaps encouraging and facilitating communication through routine use of patient-reported HRQOL instruments will allow us to better help patients make difficult treatment decisions.

\section{References}

1. Kidane B, Sulman J, Xu W, Kong QQ, Wong R, Knox JJ, et al. Baseline measure of health-related quality of life (FACT-E) is associated with overall survival in esophageal cancer patients. J Thorac Cardiovasc Surg. 2016;151:1571-80.

2. Quinten C, Martinelli F, Coens C, Sprangers MA, Ringash J, Gotay C, et al Patient Reported Outcomes and Behavioral Evidence (PROBE) and the European Organization for Research and Treatment of Cancer (EORTC) Clinical Groups. A global analysis of multitrial data investigating quality of life and symptoms as prognostic factors for survival in different tumor sites. Cancer. 2014;120: 302-11.

3. van Heijl M, Sprangers MA, de Boer AG, Lagarde SM, Reitsma HB, Busch OR, et al. Preoperative and early postoperative quality of life predict survival in potentially curable patients with esophageal cancer. Ann Surg Oncol. 2010;17: 23-30.

4. Darling G, Eton DT, Sulman J, Casson AG, Celia D. Validation of the functional assessment of cancer therapy esophageal cancer subscale. Cancer. 2006;107: 854-63.

Access to The Journal of Thoracic and Cardiovascular Surgery Online is reserved for print subscribers!

Full-text access to The Journal of Thoracic and Cardiovascular Surgery Online is available for all print subscribers. To activate your individual online subscription, please visit The Journal of Thoracic and Cardiovascular Surgery Online, point your browser to http://www.mosby.com/jtcvs, follow the prompts to activate your online access, and follow the instructions. To activate your account, you will need your subscriber account number, which you can find on your mailing label (note: the number of digits in your subscriber account number varies from 6 to 10 ). See the example below in which the subscriber account number has been circled:

\section{Sample mailing label}

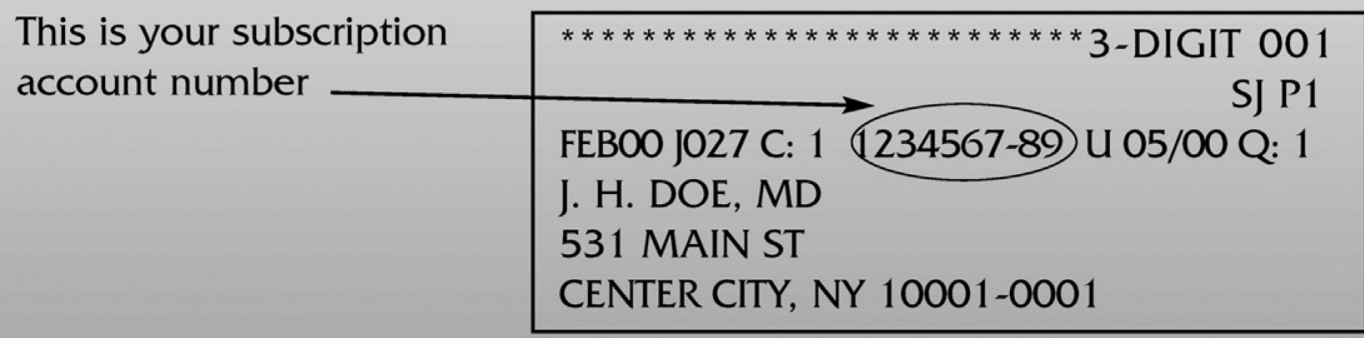

Personal subscriptions to The Joumal of Thoracic and Cardiovascular Surgery Online are for individual use only and may not be transferred. Use of The Journal of Thoracic and Cardiovascular Surgery Online is subject to agreement to the terms and conditions as indicated online. 